\title{
Advancing Pharmacological Treatments for Opioid Use Disorder (ADaPT-OUD): an Implementation Trial in Eight Veterans Health Administration Facilities
}

\author{
Hildi J. Hagedorn, $P h D^{1,2}$, Allison M. Gustavson, DPT, $P h D^{7}$, \\ Princess E. Ackland, PhD, MSPH ${ }^{1,3}$, Ann Bangerter, BS ${ }^{7}$, \\ Mark Bounthavong, PharmD, PhD ${ }^{4,5}$, Barbara Clothier, $M S, M A^{7}$, \\ Alex H. S. Harris, PhD, MS ${ }^{6,7}$, Marie E. Kenny, BA' , Siamak Noorbaloochi, PhD ${ }^{1,3}$, \\ Hope A. Salameh, $B A^{7}$, and Adam J. Gordon, $M D, M P H^{8,9}$
}

\begin{abstract}
${ }^{1}$ Center for Care Delivery \& Outcomes Research, Minneapolis Veterans Affairs Health Care System, 1 Veterans Drive, Mil Code \# 152, Minneapolis, MN, USA; ${ }^{2}$ Department of Psychiatry, School of Medicine, University of Minnesota, Minneapolis, MN, USA; ${ }^{3}$ Department of Medicine, University of Minnesota, Minneapolis, MN, USA; ${ }^{4}$ Health Economics Resource Center, Palo Alto Veterans Affairs Health Care System, Palo Alto, CA, USA; 5 Skaggs School of Pharmacy \& Pharmaceutical Sciences, University of California San Diego, San Diego, CA, USA; ${ }^{6}$ Center for Innovation To Implementation, Palo Alto Veterans Affairs Health Care System, Palo Alto, CA, USA; 'Department of Surgery, School of Medicine, Stanford University, Stanford, CA, USA; ${ }^{8}$ Vulnerable Veteran Innovative PACT (VIP) Initiative; Informatics, Decision-Enhancement, and Analytic Sciences Center (IDEAS, Salt Lake City Veterans Affairs Health Care System, 500 Foothill Drive, Salt Lake City, UT, USA; ${ }^{9}$ Program for Addiction Research, Clinical Care, Knowledge and Advocacy (PARCKA), University of Utah School of Medicine, Department of Internal Medicine, University of Utah School of Medicine, Salt Lake City, UT, USA.
\end{abstract}

BACKGROUND: Identifying effective strategies to improve access to medication treatments for opioid use disorder (MOUD) is imperative. Within the Veterans Health Administration (VHA), provision of MOUD varies significantly, requiring development and testing of implementation strategies that target facilities with low provision of MOUD.

OBJECTIVE: Determine the effectiveness of external facilitation in increasing the provision of MOUD among VHA facilities with low baseline provision of MOUD compared to matched controls.

DESIGN: Pre-post, block randomized study designed to compare facility-level outcomes in a stratified sample of eligible facilities. Four blocks (two intervention facilities in each) were defined by median splits of both the ratio of patients with OUD receiving MOUD and number of patients with OUD not currently receiving MOUD (i.e., number of actionable patients). Intervention facilities participated in a 12-month implementation intervention.

PARTICIPANTS: VHA facilities in the lowest quartile of MOUD provision (35 facilities), eight of which were randomly assigned to participate in the intervention (two per block) with twenty-seven serving as matched controls by block.

INTERVENTION: External facilitation included assessment of local barriers/facilitators, formation of a local implementation team, a site visit for action planning and training/education, cross-facility quarterly calls, monthly coaching calls, and consultation.

MAIN MEASURES: Pre- to post-change in the facility-level ratio of patients with an OUD diagnosis receiving MOUD compared to control facilities.

Prior Presentations: none

Received July 22, 2021

Accepted November 5, 2021

Published online January 3, 2022
KEY RESULTS: Intervention facilities significantly increased the ratio of patients with OUD receiving MOUD from an average of $18 \%$ at baseline to $30 \% 1$ year later, with an absolute difference of $12 \%$ (95\% confidence interval [CI]: $6.6 \%, 17.0 \%$ ). The difference in differences between intervention and control facilities was 3.0\% $(95 \%$ CI: $-0.2 \% .6 .7 \%$ ). The impact of the intervention varied by block, with smaller, less complex facilities more likely to outperform matched controls.

CONCLUSIONS: Intensive external facilitation improved the adoption of MOUD in most low-performing facilities and may enhance adoption beyond other interventions less tailored to individual facility contexts.

KEYWORDS: Substance use disorder; Medication treatment for opioid use disorder; Implementation science; External facilitation; Adoption; Evidence-based practice.

J Gen Intern Med 37(14):3594-602

DOI: $10.1007 / \mathrm{s} 11606-021-07274-7$

(C) This is a U.S. government work and not under copyright protection in the U.S.; foreign copyright protection may apply 2021

\section{BACKGROUND}

Opioid use disorder (OUD) poses substantial risks to human life and has long-term, adverse implications for healthcare utilization, risk of infectious disease, ${ }^{1,2}$ societal costs, ${ }^{3,4}$ and quality of life. ${ }^{5}$ Medication treatments for opioid use disorder (MOUD) - including formulations of buprenorphine, methadone, and naltrexone (injectable only) — are the evidencebased, guideline-recommended treatments for OUD. ${ }^{6-12} \mathrm{Bu}-$ prenorphine and naltrexone can be provided in outpatient settings (e.g., primary care, mental health), which allows for greater access to care through lower regulatory burden. However, most individuals with OUD never receive MOUD. ${ }^{13-17}$ 
As such, increasing access to MOUD is a US priority, including within the Veterans Health Administration (VHA).

The VHA includes the largest system for substance use disorder (SUD) care in the USA. ${ }^{18}$ The VHA's efforts over the past decade to improve access to MOUD through mandates, national initiatives, guidelines, and using the facilitylevel ratio of patients who receive MOUD to patients with OUD diagnoses (MOUD/OUD ratio) as a quarterly performance metric have resulted in a substantial increase in MOUD. ${ }^{17,19,20}$ However, access to MOUD care among the 140 VHA facilities varies widely from 1 to $68 \%{ }^{15}$ with some facilities lagging in the provision of MOUD care both in SUD specialty clinics and other outpatient clinics.

Applying intensive implementation strategies at facilities with low baseline provision of MOUD may improve MOUD uptake. External facilitation is an evidence-based implementation intervention and differs from national, top-down VHA efforts by empowering local clinical teams, building on local resources and strengths, tailoring strategies to specific facilitylevel barriers, and promoting sustained attention to implementation. ${ }^{21}$ External facilitation has been used successfully within VHA to implement other behavioral health interventions including hepatitis prevention services and integration of mental health services into primary care clinics. ${ }^{22-24} \mathrm{We}$ sought to examine the impact of external facilitation on MOUD implementation within eight VHA facilities that had low rates of baseline MOUD provision, as measured at the facility level by MOUD/OUD ratio (primary outcome). Testing strategies to increase the adoption of MOUD in settings with low MOUD provision is essential to improving access to MOUD and optimizing outcomes for patients with OUD.

\section{METHODS}

\section{Study Design}

The Advancing Pharmacological Treatments for Opioid Use Disorder (ADaPT-OUD) study used a 12-month intensive external facilitation strategy to improve the provision of MOUD in eight VHA facilities in the lowest quartile of MOUD/OUD performance among all VHA facilities. ${ }^{25}$ This pre-post block randomized study was designed to compare facility-level outcomes.

\section{Eligible Facilities}

VHA facilities $(N=140)$ are located across the USA and provide interdisciplinary healthcare services to veterans. Eligible facilities $(N=35)$ were VHA facilities in the lowest quartile of performance on the MOUD/OUD ratio among all VHA facilities as of October 2017 (time of eligibility). We characterized facilities by collecting rurality and facility complexity from administrative data warehouses. Rurality was extracted from the Veteran Affairs Site Tracking (VAST) system that provides classification based on the Rural-Urban Commuting Areas (RUCA) system. ${ }^{26}$ Facility complexity in the VHA is categorized into five groups (highest complexity [level 1a], high complexity [level 1b], mid-high complexity [level 1c], medium complexity [level 2], and low complexity [level 3]) based on the volume of patients, number of high-risk patients, existence of complex clinical programs, and presence of research/education infrastructure. The model that created these five facility complexity groups uses a hierarchical clustering method to assign each medical facility to a group. This method of grouping medical facilities was based on work by Bazzoli and colleagues, ${ }^{27,28}$ but the specific variables used were revised to maximize relevance specifically to VHA facilities.

\section{Randomization and Matching}

Facilities were assigned to blocks based on a median split of the MOUD/OUD ratio and number of actionable patients (e.g., patients with OUD diagnoses not currently receiving MOUD): (1) low/low, (2) high/low, (3) low/high, and (4) high/high. Note that all facilities had low MOUD/OUD ratios compared to all other VHA facilities. "High" in this context is relative to the other facilities with low provision of MOUD. Facilities were stratified in this manner as it was expected that baseline rates of MOUD provision and patient load could impact implementation efforts. For example, facilities already implementing MOUD to a substantial portion of patients or with smaller numbers of patients with OUD to manage might have an easier time expanding MOUD provision than those with limited provision and/or very large numbers of patients to manage.

From each block, two facilities were randomly selected, and SUD specialty care clinic leadership was approached to request facility-level participation in the intervention. If SUD leadership at a randomly chosen facility declined participation, another facility from that block was randomly selected to be approached next for recruitment. This process continued until each block had two intervention facilities. Leadership from five facilities declined participation. One additional facility agreed to participate but rescinded agreement shortly before they were to start the implementation phase and was replaced with another randomly selected facility from the same block. Within each block, the remaining facilities were assigned as controls. All control facilities were assigned to one intervention facility resulting in each intervention facility having two to four unique control facilities.

Intervention facilities were scheduled to start the intervention at an approximate rate of two per quarter from March 2018 to February 2019. However, one intervention facility dropped out immediately prior to the start of their intervention period and, as a result, the final replacement facility started in June 2019. We used the Standards for Reporting Implementation Studies (StaRI) checklist to report this implementation 
study (Appendix 1). ${ }^{29}$ Ethical approval was obtained from the Veterans Affairs Institutional Review Board (\#16-23).

\section{Implementation Intervention}

Starting with leadership and clinicians from the SUD specialty clinics, key stakeholders at intervention facilities were identified using a snowball technique and interviewed to identify local barriers and facilitators to MOUD implementation. In qualitative research, the snowball sampling technique refers to identifying one or two people as participants and relying on those individuals to identify additional participants. ${ }^{30}$ Interviewees included hospital and clinic leadership and clinicians from a variety of clinics including primary care, general mental health, and pain clinics. Interview data were compiled into a comprehensive facility summary report using rapid qualitative analysis techniques, which are published elsewhere. ${ }^{31-33}$ The report included the facility's facilitators, barriers, and potential resource needs to increase MOUD provision. Onsite visits were scheduled over 1 to 2 days. Facilities were asked to identify a group of key stakeholders (e.g., facility leaders and clinicians across specialty SUD and general healthcare environments) to serve as the local implementation team. The facility visits consisted of a review of the facility summary report, identification of goals and strategies for local implementation, and education for a broader clinical audience on MOUD topic areas and available resources. X-waiver certification education on buprenorphine prescribing required for providers to prescribe buprenorphine was offered to all facilities; seven of the eight facilities chose to hold this training during the on-site visit. ${ }^{34}$ Facility visits were followed by 12 months of external facilitation, including monthly coaching calls, quarterly cross-facility community of practice calls, quarterly facility-level feedback reports including key metrics, and access to expert consultation on MOUD practices. Details on the strategies included in the external facilitation intervention are described in Table 1 and published elsewhere. ${ }^{25}$.

\section{Outcomes}

The primary outcome was the MOUD/OUD ratio as this is the performance metric related to OUD treatment familiar to VHA providers and administrators. The numerator of the MOUD/OUD ratio includes patients receiving buprenorphine, methadone, or naltrexone (injectable only). The ADAPTOUD intervention focused primarily on buprenorphine education and implementation due to the lower regulatory burden of prescribing compared to methadone and the higher level of evidence of effectiveness compared to injectable naltrexone. Therefore, the number of patients with OUD diagnoses receiving a prescription for buprenorphine within the previous 6 months was included as a secondary measure to confirm the impact of the intervention on buprenorphine prescribing specifically.
The MOUD/OUD ratio is updated nightly and reported quarterly on a clinical dashboard that can be regularly viewed by VHA operational leadership and clinical partners to evaluate their facility's performance compared to national trends. As such, this ratio was accessible to researchers, stakeholders, and clinicians for timely, transparent discussion regarding progress in the context of the external facilitation implementation intervention. Baseline MOUD/OUD ratios were extracted for the quarter prior to the facility visit date because facilities had differing intervention start dates that spanned a 16-month period. Post-intervention MOUD/OUD ratios were extracted for the quarter that included the 1-year post on-site visit date. The secondary outcome, the number of patients with OUD diagnoses who received a prescription for buprenorphine within the previous 6 months, is also updated nightly and reported quarterly and was extracted from VHA administrative data at the same quarterly time points as the primary outcome measure.

\section{Statistical Analysis}

For the intervention facilities, we compared the mean baseline ratio of MOUD/OUD (quarter prior to site visit) to the mean MOUD/OUD ratio captured 12 months after the on-site visit with a $95 \%$ confidence interval about this mean. To analyze the data comparing each intervention facility to its matched control facilities, we used a difference-in-differences (DIDs) approach (ratio of MOUD/OUD at the 12-month post on-site visit minus baseline). We did this same analysis for each block and for an overall comparison of intervention facilities to control facilities. The DIDs were bootstrapped with 1000 replicates to construct 95\% confidence intervals about the sample mean DID by each intervention facility compared to its controls, by block, and for an overall comparison of intervention facilities to control facilities. Analyses were performed using SAS® 9.4 (Cary, NC, USA) and R (R Core Team 2020, Vienna, Austria).

\section{Sensitivity Analysis}

One intervention facility (D2) differed from the other intervention facilities in several key factors. This facility replaced an original facility that dropped out immediately prior to the start of their intervention phase. Therefore, this facility started the implementation phase 4 months later than the others. In addition, this facility had the longest period of time between the determination of eligibility for the study (October 2017) and the baseline assessment of outcome measures (June 2019). During the intervening 20 months, the MOUD/OUD ratio at the facility dramatically improved. Finally, because their intervention period ran from June 2019 to June 2020, they were the only facility to be directly impacted by the coronavirus 2019 pandemic during their intervention period. We conducted a sensitivity analysis that excluded this facility using the same analytic methods described above because of these unique circumstances. 
Table 1 Detailed Description of the Implementation Strategies Selected Based on Literature and Expert Recommendations ${ }^{37,38}$

\begin{tabular}{|c|c|c|c|c|c|}
\hline $\begin{array}{l}\text { Implementation } \\
\text { strategy }\end{array}$ & $\begin{array}{l}\text { Who enacts the } \\
\text { strategy? }\end{array}$ & $\begin{array}{l}\text { What are the actions, steps, } \\
\text { or processes enacted? }\end{array}$ & $\begin{array}{l}\text { Who was the } \\
\text { implementation } \\
\text { target? }\end{array}$ & $\begin{array}{l}\text { When was the } \\
\text { strategy used? }\end{array}$ & $\begin{array}{l}\text { What was the } \\
\text { dosage of the } \\
\text { strategy? }\end{array}$ \\
\hline Facilitation & $\begin{array}{l}\text { External } \\
\text { facilitators }\end{array}$ & $\begin{array}{l}\text { Interact with facility throughout } \\
\text { intervention }\end{array}$ & $\begin{array}{l}\text { Local implementation } \\
\text { teams }\end{array}$ & $\begin{array}{l}\text { Throughout } \\
\text { intervention year }\end{array}$ & $\begin{array}{l}\text { Minimum of one 2- } \\
\text { day site visit and } \\
\text { monthly calls with as- } \\
\text { needed consultation }\end{array}$ \\
\hline $\begin{array}{l}\text { Conduct local needs } \\
\text { assessment }\end{array}$ & Qualitative core & Interview local stakeholders & Local stakeholders & Prior to site visit & $\begin{array}{l}\text { Up to } 10 \text { interviews } \\
\text { per facility }\end{array}$ \\
\hline $\begin{array}{l}\text { Identify barriers and } \\
\text { facilitators }\end{array}$ & Qualitative core & $\begin{array}{l}\text { Rapid analysis of stakeholder } \\
\text { interviews to formulate facility } \\
\text { report }\end{array}$ & $\begin{array}{l}\text { Local implementation } \\
\text { teams }\end{array}$ & Prior to site visit & $\mathrm{N} / \mathrm{A}$ \\
\hline $\begin{array}{l}\text { Capture and share } \\
\text { local knowledge }\end{array}$ & $\begin{array}{l}\text { External } \\
\text { facilitators }\end{array}$ & $\begin{array}{l}\text { Review of local facility report } \\
\text { with local implementation } \\
\text { teams }\end{array}$ & $\begin{array}{l}\text { Local implementation } \\
\text { teams }\end{array}$ & During site visit & $\begin{array}{l}2 \mathrm{~h} \text { during site visit } \\
\text { dedicated to } \\
\text { reviewing and } \\
\text { verifying site report }\end{array}$ \\
\hline $\begin{array}{l}\text { Identify and prepare } \\
\text { champions }\end{array}$ & $\begin{array}{l}\text { External } \\
\text { facilitators }\end{array}$ & $\begin{array}{l}\text { Champions identified through } \\
\text { pre-intervention interviews, site } \\
\text { visit planning process, and in- } \\
\text { teractions during site visit }\end{array}$ & Local stakeholders & $\begin{array}{l}\text { Prior to and during } \\
\text { site visit }\end{array}$ & $\mathrm{N} / \mathrm{A}^{\circ}$ \\
\hline $\begin{array}{l}\text { Conduct educational } \\
\text { meetings }\end{array}$ & Clinical expert & $\begin{array}{l}\text { Requested educational } \\
\text { offerings presented during site } \\
\text { visit }\end{array}$ & Facility clinicians & During site visit & $8 \mathrm{~h}$ during site visit \\
\hline $\begin{array}{l}\text { Organize clinician } \\
\text { implementation } \\
\text { meetings }\end{array}$ & $\begin{array}{l}\text { External } \\
\text { facilitators }\end{array}$ & $\begin{array}{l}\text { Facility coaching calls; cross- } \\
\text { facility community of practice } \\
\text { calls }\end{array}$ & $\begin{array}{l}\text { Facility } \\
\text { implementation teams }\end{array}$ & $\begin{array}{l}\text { Facility: during } \\
\text { facility intervention } \\
\text { year } \\
\text { Cross-facility: } \\
\text { while any sites } \\
\text { were active in } \\
\text { intervention }\end{array}$ & $\begin{array}{l}\text { Facility: } 1 / \text { month } \times 12 \\
\text { months } \\
\text { Cross-facility: } 1 /- \\
\text { quarter } \times 8 \text { quarters }\end{array}$ \\
\hline Audit and feedback & $\begin{array}{l}\text { External } \\
\text { facilitators }\end{array}$ & $\begin{array}{l}\text { Provide facility implementation } \\
\text { team with report of main } \\
\text { implementation outcomes }\end{array}$ & $\begin{array}{l}\text { Facility } \\
\text { implementation teams }\end{array}$ & $\begin{array}{l}\text { During facility } \\
\text { intervention year }\end{array}$ & $\begin{array}{l}\text { Quarterly for } 4 \\
\text { quarters }\end{array}$ \\
\hline $\begin{array}{l}\text { Change in } \\
\text { credentialing or } \\
\text { licensure standards }\end{array}$ & $\begin{array}{l}\text { External } \\
\text { facilitators along } \\
\text { with VHA } \\
\text { national } \\
\text { leadership }\end{array}$ & $\begin{array}{l}\text { Release of national notification } \\
\text { instructing facilities not to } \\
\text { place additional credentialing/ } \\
\text { privileging requirements on } \\
\text { new prescribers beyond docu- } \\
\text { mentation of X-waiver }\end{array}$ & $\begin{array}{l}\text { Credentialing and } \\
\text { privileging } \\
\text { departments at VHA } \\
\text { facilities }\end{array}$ & $\begin{array}{l}\text { Notification } \\
\text { published October } \\
2019\end{array}$ & N/A \\
\hline $\begin{array}{l}\text { Develop/distribute } \\
\text { educational materials }\end{array}$ & $\begin{array}{l}\text { External } \\
\text { facilitators }\end{array}$ & $\begin{array}{l}\text { Facilitators compiled a large } \\
\text { library of print and online } \\
\text { materials addressing various } \\
\text { educational needs; provided to } \\
\text { facilities as requested to } \\
\text { address knowledge gaps }\end{array}$ & $\begin{array}{l}\text { Facility } \\
\text { implementation teams } \\
\text { and clinicians }\end{array}$ & $\begin{array}{l}\text { Throughout } \\
\text { intervention period }\end{array}$ & As requested \\
\hline $\begin{array}{l}\text { Provide ongoing } \\
\text { consultation }\end{array}$ & Clinical expert & $\begin{array}{l}\text { Clinical expert available as } \\
\text { needed to consult regarding } \\
\text { clinical care }\end{array}$ & Facility clinicians & $\begin{array}{l}\text { Throughout } \\
\text { intervention period }\end{array}$ & As requested \\
\hline Tailor strategies & $\begin{array}{l}\text { External } \\
\text { facilitators }\end{array}$ & $\begin{array}{l}\text { External facilitators used } \\
\text { information from site reports, } \\
\text { site visits, and facilitation calls } \\
\text { to identify barriers to } \\
\text { implementation and provide } \\
\text { facilities with needed resources }\end{array}$ & $\begin{array}{l}\text { Facility } \\
\text { implementation team } \\
\text { and clinicians }\end{array}$ & $\begin{array}{l}\text { Throughout } \\
\text { intervention period }\end{array}$ & N/A \\
\hline
\end{tabular}

*Cross-facility conference calls ran from 3 months after the first sites started the intervention until the last site completed the intervention for a total of 8 calls in 24 months

\section{RESULTS}

\section{Facility Characteristics}

Facility characteristics, including facility complexity and rurality, at the time of eligibility are outlined by block (Table 2). The MOUD/OUD ratio ranged from 3.7 to $19.4 \%$ for intervention facilities $(N=8)$ and 5.0 to $20.0 \%$ for matched control facilities $(N=27,2-4$ matched controls per intervention facility). The number of actionable patients ranged from 141 to 955 for intervention facilities and 88 to 1757 for matched control facilities.

\section{MOUD/OUD Ratio}

Table 3 presents the changes in MOUD/OUD ratio at the intervention facilities and control facilities, as well as the DID analysis comparing intervention and matched control facilities from pre- to post-implementation. All intervention facilities, with the exception of D2 (mentioned above in sensitivity analysis), had increases on the MOUD/OUD ratio from pre- to post-implementation. Overall, there was a significant increase in the MOUD/OUD ratio for intervention facilities of $12 \%$ (95\% confidence interval [CI]: 6.6\%, 17.4\%). Control 
Table 2 Facility Characteristics by Block at the Time of Eligibility

\begin{tabular}{|c|c|c|c|c|c|}
\hline Block $^{*}$ & $\begin{array}{l}\text { Intervention-control facility } \\
\text { identification }\end{array}$ & $\begin{array}{l}\text { MOUD/OUD } \\
\text { ratio }^{\dagger}\end{array}$ & $\begin{array}{l}\# \text { of actionable } \\
\text { patients }\end{array}$ & $\begin{array}{l}\text { Facility } \\
\text { complexity }\end{array}$ & $\begin{array}{l}\text { Urban or } \\
\text { rural }\end{array}$ \\
\hline \multirow{10}{*}{$\begin{array}{l}\text { A: low MOUD/OUD and low \# of } \\
\text { actionable patients }\end{array}$} & Intervenion-A1 & $3.7 \%$ & 141 & 3: low & Rural \\
\hline & Control-1 & $6.3 \%$ & 252 & 1c: mid-high & Urban \\
\hline & Control-2 & $6.3 \%$ & 300 & 1c: mid-high & Urban \\
\hline & Control-3 & $8.3 \%$ & 210 & 3: low & Rural \\
\hline & Control-4 & $11.7 \%$ & 335 & 2: medium & Urban \\
\hline & Intervention-A2 & $8.5 \%$ & 238 & 2: medium & Rural \\
\hline & Control-1 & $6.2 \%$ & 289 & 2: medium & Urban \\
\hline & Control-2 & $9.3 \%$ & 297 & 2: medium & Urban \\
\hline & Control-3 & $12.4 \%$ & 305 & 3: low & Urban \\
\hline & Control-4 & $13.8 \%$ & 432 & 3: low & Urban \\
\hline \multirow{8}{*}{$\begin{array}{l}\text { B: high MOUD/OUD and low \# of } \\
\text { actionable patients }\end{array}$} & Intervention-B1 & $15.6 \%$ & 178 & 3: low & Urban \\
\hline & Control-1 & $15.3 \%$ & 164 & 2: medium & Rural \\
\hline & Control-2 & $15.4 \%$ & 88 & 2: medium & Urban \\
\hline & Control-3 & $18.6 \%$ & 128 & 2: medium & Urban \\
\hline & Intervention-B2 & $18.8 \%$ & 411 & 2: medium & Urban \\
\hline & Control-1 & $15.5 \%$ & 374 & 1c: mid-high & Urban \\
\hline & Control-2 & $16.4 \%$ & 550 & 1c: mid-high & Urban \\
\hline & Control-3 & $19.1 \%$ & 441 & 1c: mid-high & Urban \\
\hline \multirow{7}{*}{$\begin{array}{l}\text { C: low MOUD/OUD and high \# of } \\
\text { actionable patients }\end{array}$} & Intervention-C1 & $5.1 \%$ & 629 & 3: low & Urban \\
\hline & Control-1 & $5.0 \%$ & 453 & 3: low & Urban \\
\hline & Control-2 & $9.1 \%$ & 472 & 1a: highest & Urban \\
\hline & Intervention-C2 & $13.7 \%$ & 647 & 3: low & Urban \\
\hline & Control-1 & $12.3 \%$ & 540 & 1c: mid-high & Urban \\
\hline & Control-2 & $14.0 \%$ & 1416 & 1c: mid-high & Urban \\
\hline & Control-3 & $14.7 \%$ & 1040 & 1b: high & Urban \\
\hline \multirow{10}{*}{$\begin{array}{l}\text { D: high MOUD/OUD and high \# of } \\
\text { actionable patients }\end{array}$} & Intervention-D1 & $13.9 \%$ & 871 & 1a: highest & Urban \\
\hline & Control-1 & $15.7 \%$ & 1757 & 1c: mid-high & Urban \\
\hline & Control-2 & $16.7 \%$ & 593 & 1b: highest & Urban \\
\hline & Control-3 & $17.0 \%$ & 796 & 1c: mid-high & Urban \\
\hline & Control-4 & $19.4 \%$ & 618 & 1c: mid-high & Rural \\
\hline & Intervention-D2 & $19.4 \%$ & 955 & 1b: high & Urban \\
\hline & Control-1 & $17.7 \%$ & 690 & 1c: mid-high & Rural \\
\hline & Control-2 & $19.0 \%$ & 512 & 1c: mid-high & Urban \\
\hline & Control-3 & $19.1 \%$ & 529 & 3: low & Rural \\
\hline & Control-4 & $20.0 \%$ & 577 & 2: medium & Urban \\
\hline
\end{tabular}

*The four blocks, collectively, were in the lowest quartile for MOUD/OUD ratios out of all $140 \mathrm{VHA}$ facilities at the time of eligibility. Blocks consisted of facilities grouped by how they compared to the median MOUD/OUD ratio and the median number of actionable patients. The medians were the cutoffs to determine low and high groups of each on these two facility-level variables

Calculated as of quarter-level data (July-September) 2017

Calculated as of October 6, 2017

${ }^{\S}$ Facility complexity model in the VHA is categorized into five groups (highest complexity [level 1a], high complexity [level 1b], mid-high complexity [level 1c], medium complexity [level 2], and low complexity [level 3]) based on the volume of patients, number of high-risk patients, existence of complex clinical programs, and presence research/education infrastructure

facilities also demonstrated an increase in the MOUD/OUD ratio with an overall mean increase of $9 \%$ (95\% CI: $6.7 \%$, $11.4 \%)$. The overall DID between all intervention and control facility MOUD/OUD ratios was positive at 3.0\%, but not significant (95\% CI: $-0.2 \%, 6.7 \%)$. Block B (high MOUD/OUD and low \# of actionable patients) and block C (low MOUD/OUD and high \# of actionable patients) demonstrated significant DIDs of $6.9 \%$ (95\% CI: $2.5 \%, 10.7 \%)$ and $9.0 \%$ (95\% CI: $4.8 \%, 13.2 \%$ ), respectively. For block A (low MOUD/OUD and low number of actionable patients), the DID was positive at $4.0 \%$ but not significant $(95 \% \mathrm{CI}$ :$0.2 \%, 8.7 \%$ ). Block D (high MOUD/OUD and high \# of actionable patients) showed a significant DID of $-7.8 \%$ (95\% CI: $-11.3 \%,-4.0 \%)$.

\section{Number of Patients Prescribed Buprenorphine}

Table 4 presents the facility-level differences in the number of patients prescribed buprenorphine for both intervention and control facilities, as well as the DID analysis comparing intervention and matched control facilities from pre- to postimplementation. The results for the number of patients prescribed buprenorphine mirror those for the MOUD/OUD ratio. All intervention facilities, with the exception of D2, had increases in number of patients prescribed buprenorphine from pre- to post-implementation. Overall, there was a significant increase in patients prescribed buprenorphine for the intervention facilities from pre- to post-implementation (mean 41.8, 95\% CI: 18.3, 61.0). Control facilities also demonstrated an increase in the number of patients prescribed buprenorphine (mean 29.4, 95\% CI: 15.9, 41.6). The overall DID between intervention and control facilities for the number of patients prescribed buprenorphine was positive but not significant at 13.2 (95\% CI: - 4.8, 31.0). Block A (low MOUD/OUD and low \# of actionable patients) and block B (high MOUD/OUD and low \# of actionable patients) demonstrated significant DIDs of 21.3 patients $(95 \%$ CI: 4.3, 33.0) and 33.0 (95\% CI: 
Table 3 Difference in Differences in MOUD/OUD Between Intervention and Control Facilities from Pre- to 12 Months Post-Facilitation

\begin{tabular}{|c|c|c|c|c|c|c|c|c|c|}
\hline \multirow[t]{2}{*}{ Block $^{*}$} & \multirow[t]{2}{*}{$\begin{array}{l}\text { Intervention } \\
\text { facilities }\end{array}$} & \multicolumn{3}{|c|}{$\begin{array}{l}\text { Intervention facilities } \\
\text { MOUD/OUD }\end{array}$} & \multicolumn{3}{|c|}{$\begin{array}{l}\text { Control facilities } \\
\text { MOUD/OUD }\end{array}$} & \multicolumn{2}{|c|}{ Difference in differences } \\
\hline & & $\operatorname{Pre}^{\dagger}$ & Post & Difference & $\operatorname{Pre}^{\dagger}$ & Post ${ }^{*}$ & $\overline{\text { Difference }}$ & $\begin{array}{l}\text { Difference in } \\
\text { differences }{ }^{\S}\end{array}$ & $95 \% \mathrm{CI}^{\mathrm{II}}$ \\
\hline \multirow{3}{*}{$\begin{array}{l}\text { A: low MOUD/OUD and } \\
\text { low \# of actionable } \\
\text { patients }\end{array}$} & A1 & $4.0 \%$ & $18.2 \%$ & $14.2 \%$ & $9.2 \%$ & $19.4 \%$ & $10.2 \%$ & $4.0 \%$ & \multirow{6}{*}{$\begin{array}{l}(-1.5 \%, \\
8.5 \%) \\
(-3.5 \%, \\
11.7 \%) \\
(-0.2 \%, \\
\mathbf{8 . 7 \% )} \\
(-0.2 \%, \\
15.4 \%) \\
(1.5 \%, \\
8.6 \%) \\
(\mathbf{2 . 5 \%}, \\
\mathbf{1 0 . 7 \% )}\end{array}$} \\
\hline & $\mathrm{A} 2$ & $10.3 \%$ & $26.2 \%$ & $15.9 \%$ & $21.0 \%$ & $32.8 \%$ & $11.8 \%$ & $4.1 \%$ & \\
\hline & Block A mean & $7.2 \%$ & $22.2 \%$ & $15.0 \%$ & $15.1 \%$ & $26.1 \%$ & $11.0 \%$ & $4.0 \%$ & \\
\hline \multirow{3}{*}{$\begin{array}{l}\text { B: high MOUD/OUD } \\
\text { and low \# of actionable } \\
\text { patients }\end{array}$} & B1 & $15.6 \%$ & $35.9 \%$ & $20.3 \%$ & $18.6 \%$ & $30.9 \%$ & $12.3 \%$ & $8.0 \%$ & \\
\hline & B2 & $32.9 \%$ & $42.4 \%$ & $9.5 \%$ & $22.9 \%$ & $26.6 \%$ & $3.7 \%$ & $5.8 \%$ & \\
\hline & Block B mean & $24.2 \%$ & $39.2 \%$ & $15.0 \%$ & $20.7 \%$ & $28.8 \%$ & $8.1 \%$ & $6.9 \%$ & \\
\hline \multirow{3}{*}{$\begin{array}{l}\text { C: low MOUD/OUD and } \\
\text { high \# of actionable } \\
\text { patients }\end{array}$} & $\mathrm{C} 1$ & $5.2 \%$ & $26.1 \%$ & $20.9 \%$ & $9.6 \%$ & $19.3 \%$ & $9.7 \%$ & $11.2 \%$ & \multirow{3}{*}{$\begin{array}{l}(8.0 \%, \\
14.6 \%) \\
(2.8 \%, \\
10.7 \%) \\
(\mathbf{4 . 8 \%}, \\
\mathbf{1 3 . 2 \% )}\end{array}$} \\
\hline & $\mathrm{C} 2$ & $18.6 \%$ & $31.3 \%$ & $12.7 \%$ & $26.4 \%$ & $32.2 \%$ & $5.8 \%$ & $6.9 \%$ & \\
\hline & Block C mean & $11.9 \%$ & $28.7 \%$ & $16.8 \%$ & $18.0 \%$ & $25.8 \%$ & $7.8 \%$ & $9.0 \%$ & \\
\hline \multirow{3}{*}{$\begin{array}{l}\text { D: high MOUD/OUD } \\
\text { and high \# of actionable } \\
\text { patients }\end{array}$} & D1 & $22.4 \%$ & $26.1 \%$ & $3.7 \%$ & $17.8 \%$ & $28.3 \%$ & $10.5 \%$ & $-6.8 \%$ & \multirow{3}{*}{$\begin{array}{l}(-10.1 \%, \\
-1.0 \%) \\
(-14.6 \%, \\
-4.7 \%) \\
(-\mathbf{1 1 . 3 \%}, \\
-\mathbf{4 . 0 \%})\end{array}$} \\
\hline & D2 & $34.9 \%$ & $33.5 \%$ & $-1.4 \%$ & $28.6 \%$ & $36.0 \%$ & $7.4 \%$ & $-8.9 \%$ & \\
\hline & Block D mean & $28.7 \%$ & $29.8 \%$ & $1.1 \%$ & $23.2 \%$ & $32.1 \%$ & $8.9 \%$ & $-7.8 \%$ & \\
\hline Total & Overall mean & $18.0 \%$ & $\mathbf{3 0 . 0} \%$ & $12.0 \%$ & $19.2 \%$ & $28.2 \%$ & $9.0 \%$ & $3.0 \%$ & $\begin{array}{l}(-0.2 \% \\
6.7 \%)\end{array}$ \\
\hline
\end{tabular}

*The four blocks were defined by being in the lowest quartile for MOUD/OUD ratios out of all 140 VHA facilities at the time of eligibility. Blocks consisted of the median MOUD/OUD ratio, and the median number of actionable patients were the cut-offs to determine low and high groups of each on these two facility-level variables

Data were extracted from the quarter just prior to the facility visit date

${ }^{7}$ Data were extracted from the quarter that included the 1-year post facility visit date

${ }^{s}$ Difference in differences is post minus pre for each intervention facility minus the mean post-pre of its matched control facilities

"95\% confidence intervals (CI) bootstrapped with 1000 replicates

9.8, 52.5), respectively. Block C (low MOUD/OUD and high \# of actionable patients) DID was positive at 35.5 patients, but not significant (95\% CI: $-0.02,67.0)$. Block D (high MOUD/OUD and high \# of actionable patients) showed a significant DID of -36.9 patients (95\% CI: $-70.9,-10.0)$.

\section{Sensitivity Analysis}

As described above in the "Methods" section, facility D2 differed from other facilities in several ways. With this facility excluded, the DID between intervention and control facilities on MOUD/OUD ratio change from pre- to postimplementation was significant at $4.7 \%$ (95\% CI: $1.1 \%$, 7.9\%). The DID between intervention and control facilities on number of patients prescribed buprenorphine was also significant (23.0 patients, $95 \%$ CI: 6.1, 39.5).

\section{DISCUSSION}

The ADaPT-OUD external facilitation intervention resulted in an overall significant improvement in MOUD for facilities with low baseline provision of MOUD, as evidenced by significant increases in the MOUD/OUD ratio and number of patients prescribed buprenorphine. Intervention facilities combined treated an additional 334 patients with buprenorphine during the intervention period, which is important when considering the high rate of mortality among patients with OUD who are untreated. It is not surprising that the matched control facilities also improved. During the study period, there was national and VHA focus on addressing the opioid crisis; for example, the VHA mandated evidence-based MOUD be made available to appropriate patients in the clinical setting in which they present. ${ }^{17,19}$ Within VHA, other efforts in place to improve MOUD adoption involved the inclusion of the MOUD/OUD ratio as a key performance metric, an academic detailing campaign which provided outreach visits to providers to educate them about MOUD, and the Stepped-Care for Opioid Use Disorder Train the Trainer (SCOUTT) Initiative, ${ }^{35}$ which aimed to increase access to MOUD in non-SUD specialty care clinics. In addition, several other large research programs were aimed at impacting MOUD adoption within various environments including community-based clinics, inpatient, and emergency room settings. ${ }^{36}$.

While the overall difference in differences between intervention and control facilities was not significant, three of four intervention blocks outperformed their control sites on either 
Table 4 Difference in Differences in the Number of Patients Receiving Buprenorphine Between Intervention and Control Facilities

\begin{tabular}{|c|c|c|c|c|c|c|c|c|c|}
\hline \multirow[t]{2}{*}{$\overline{\text { Block }^{*}}$} & \multirow[t]{2}{*}{$\begin{array}{l}\text { Intervention } \\
\text { facilities }\end{array}$} & \multirow{2}{*}{$\begin{array}{l}\text { Intervention } \\
\text { facilities } \\
\# \text { of } \\
\text { buprenorphine } \\
\text { patients } \\
\text { Pre }^{\dagger}\end{array}$} & \multirow[b]{2}{*}{ Post } & \multirow[b]{2}{*}{ Difference } & \multirow{2}{*}{$\begin{array}{l}\text { Control } \\
\text { facilities } \\
\# \text { of } \\
\text { buprenorphine } \\
\text { patients } \\
\text { Pre }^{\dagger}\end{array}$} & \multirow[b]{2}{*}{ Post $^{\ddagger}$} & \multirow[b]{2}{*}{ Difference } & \multirow{2}{*}{$\begin{array}{l}\text { Difference } \\
\text { in } \\
\text { differences } \\
\begin{array}{l}\text { Difference } \\
\text { in } \\
\text { differences }\end{array}\end{array}$} & \multirow[b]{2}{*}{$\begin{array}{l}95 \% \\
\text { CIII }\end{array}$} \\
\hline & & & & & & & & & \\
\hline \multirow{3}{*}{$\begin{array}{l}\text { A: low } \\
\text { MOUD/OUD } \\
\text { and low \# of } \\
\text { actionable } \\
\text { patients }\end{array}$} & A1 & 1.0 & 36.0 & 35.0 & 4.0 & 13.5 & 9.5 & 25.5 & \multirow{13}{*}{$\begin{array}{l}(16.0, \\
33.3) \\
(- \\
11.4, \\
45.9) \\
(\mathbf{4 . 3}, \\
\mathbf{3 3 . 0}) \\
(3.0, \\
12.0) \\
(34.0, \\
72.0) \\
(\mathbf{9 . 8}, \\
\mathbf{5 2 . 5})\end{array}$} \\
\hline & A2 & 2.0 & 44.0 & 42.0 & 32.3 & 57.3 & 25 & 17.0 & \\
\hline & $\begin{array}{l}\text { Block A } \\
\text { mean }\end{array}$ & 1.5 & 40.0 & 38.5 & 18.1 & 35.4 & 17.3 & 21.3 & \\
\hline \multirow{3}{*}{$\begin{array}{l}\text { B: high } \\
\text { MOUD/OUD } \\
\text { and low \# of } \\
\text { actionable } \\
\text { patients }\end{array}$} & $\mathrm{B} 1$ & 27.0 & 39.0 & 12.0 & 15.7 & 18.7 & 3.0 & 9.0 & \\
\hline & B2 & 78.0 & 156.0 & 78.0 & 23.7 & 44.7 & 21.0 & 57.0 & \\
\hline & $\begin{array}{l}\text { Block B } \\
\text { mean }\end{array}$ & 52.5 & 97.5 & 45.0 & 19.7 & 31.7 & 12.0 & 33.0 & \\
\hline \multirow{3}{*}{$\begin{array}{l}\text { C: low } \\
\text { MOUD/OUD } \\
\text { and high \# of } \\
\text { actionable } \\
\text { patients }\end{array}$} & $\mathrm{C} 1$ & 0.0 & 36.0 & 36.0 & 4.0 & 35.0 & 31.0 & 5.0 & \\
\hline & $\mathrm{C} 2$ & 52.0 & 150.0 & 98.0 & 114.3 & 146.3 & 32.0 & 66.0 & \\
\hline & $\begin{array}{l}\text { Block C } \\
\text { mean }\end{array}$ & 26.0 & 93.0 & 67.0 & 59.2 & 90.7 & 31.5 & 35.5 & \\
\hline \multirow{3}{*}{$\begin{array}{l}\text { D: high } \\
\text { MOUD/OUD } \\
\text { and high \# of } \\
\text { actionable } \\
\text { patients }\end{array}$} & D1 & 123.0 & 156.0 & 33.0 & 109.3 & 161.0 & 51.8 & -18.8 & \\
\hline & D2 & 169.0 & 169.0 & 0.0 & 120.0 & 175.0 & 55.0 & -55.0 & \\
\hline & $\begin{array}{l}\text { Block D } \\
\text { mean }\end{array}$ & 146 & 162.5 & 16.5 & 114.6 & 168.0 & 53.4 & -36.9 & \\
\hline Total & $\begin{array}{l}\text { Overall } \\
\text { mean }\end{array}$ & 56.5 & 98.3 & 41.8 & 52.9 & 81.5 & 28.6 & 13.2 & \\
\hline
\end{tabular}

*The four blocks were defined by being in the lowest quartile for MOUD/OUD ratios out of all 140 VHA facilities at the time of eligibility. Blocks consisted of the median MOUD/OUD ratio, and the median number of actionable patients were the cut-offs to determine low and high groups of each on these two facility-level variables

Data were extracted from the quarter just prior to the facility visit date

${ }^{*}$ Data were extracted from the quarter that included the 1-year post facility visit date

$\S$ Difference in differences is post minus pre for each intervention facility minus the mean post-pre of its matched control facilities

"95\% confidence intervals (CI) bootstrapped with 1000 replicates

the MOUD/OUD ratio or the number of patients prescribed buprenorphine. In addition, a sensitivity analysis demonstrated that the removal of the one outlier site (D2) resulted in the remaining intervention facilities outperforming control facilities on both outcome measures. This provides a strong signal for the impact of facility-specific external facilitation on the adoption of MOUD beyond other, concurrent efforts. While mandates and many other national efforts assisted in raising the relative priority of MOUD access nationally, individual facilities continue to lag in optimal implementation of MOUD and additional, more intensive efforts are required to assist these facilities. These findings have important implications for organizational investment in external facilitation for healthcare settings with low adoption of MOUD. Future work will clarify the cost of the external facilitation in comparison to the impact of increased access to MOUD on patient-level healthcare expenses as well as facility, provider, and patient factors that may predict greater facility adoption of MOUD.
Despite these results, the impact of the intervention was not consistent across facilities. Block D underperformed in comparison to the other blocks. Block D included facilities that, while still low adopting compared to VHA facilities overall, were at the higher end of the MOUD/OUD ratio among intervention facilities at baseline. Because the MOUD/OUD metric is used to evaluate overall VHA facility-level performance, the lower a facility ranks on this metric, the more likely it is to draw the attention of facility-level leaders. Block D facilities were also the only intervention facilities categorized as high complexity. While high complexity indicates a higher level of resources, it also indicates greater numbers of providers, larger volumes of patients, more high-risk patients, and the presence of complex clinical programs. The combination of high volumes of actionable patients and the high complexity of the facilities may make it more difficult to establish the relationships needed to communicate and collaborate across service lines to effectively increase MOUD adoption. 


\section{Limitations}

There are limitations of our study. First, there is a potential for type II error given that the sample size was small and may not be powered to detect clinically meaningful DIDs, particularly at the block or individual facility level. Despite the nonsignificant findings, it is important for decision-makers to know that intervention facilities, on average, had greater MOUD provision after implementation. Given the small sample size, it was also not feasible to control for facility characteristics that may have impacted MOUD adoption although the difference-in-difference design focuses on differences in improvements, and in that sense, reduces the importance of baseline differences. Second, the full effect of the external facilitation implementation intervention may not have been captured in the 12-month time. We may see a further impact on MOUD provision in the sustainability period as facilities leverage the momentum garnered during the implementation period. Future work will assess for maintenance or ongoing improvement at intervention facilities during the sustainability phase. Finally, this study was conducted in the VHA system which limits generalizability to non-VHA systems. Most notably, SUD specialty care clinics are co-located within many VHA facilities. Co-location within the facility presumably makes it easier to coordinate care for patients with OUD across clinical settings.

The VHA system has distinctive aspects, including colocation of SUD specialty care and a different reimbursement structure. However, one of the key features of the external facilitation intervention described here is the flexibility to account for the unique resources, barriers, and organizational structures of a system or facility when developing facilityspecific implementation plans. Therefore, this intervention could serve as a useful model to guide other large healthcare systems and payers interested in increasing access to MOUD within various clinical settings. Future research testing the external facilitation intervention in non-VHA settings is needed to both investigate the impact of the external facilitation intervention on MOUD adoption and adapt it for other organizational contexts.

\section{CONCLUSIONS}

An intensive external facilitation intervention improved the provision of MOUD in most VHA facilities with low provision of MOUD care. The variation in impact of the intervention may be accounted for by the heterogeneity in facility characteristics, even among facilities with low provision of MOUD at baseline. Importantly, we demonstrated clinically meaningful improvements in most facilities and provided a foundation for continued gains. Healthcare systems may consider such external facilitation interventions for facilities struggling to expand provision of MOUD.
Acknowledgements: We would like to thank all of the implementation teams from our intervention facilities. We would also like to thank Dr. Karen Drexler from the VHA Office of Mental Health and Suicide Prevention for her tremendous support for our work.

Corresponding Author: Hildi J. Hagedorn, PhD; Center for Care Delivery \& Outcomes Research, Minneapolis Veterans Affairs Health Care System, 1 Veterans Drive, Mil Code \#152, Minneapolis, MN 55417, USA (e-mail: hildi.hagedorn@va.gov).

Funding This study was funded by the Veteran Administrations Health Services Research and Development Investigator Initiated Research Project \#16-145; Minneapolis Center of Innovation, Center for Care Delivery and Outcomes Research (CIN 13-406); Veteran Administrations Health Services Research and Development Informatics, Decision-Enhancement, and Analytic Sciences (IDEAS) Center of Innovation (CIN 13-414)[AJG]; and the Veterans Health Administration Office of Academic Affiliations Advanced Fellowship in Clinical and Health Services Research (TPH 67-00O). The views expressed in this article are those of the authors and do not necessarily reflect the position or policy of the Department of Veterans Affairs or the United States Government.

\section{Declarations:}

Conflict of Interest: The authors declare that they do not have a conflict of interest.

\section{REFERENCES}

1. Marsch LA. The efficacy of methadone maintenance interventions in reducing illicit opiate use, HIV risk behavior and criminality: a metaanalysis. Addiction. 1998;93(4):515-532.

2. Tsui JI, Evans JL, Lum PJ, Hahn JA, Page K. Association of opioid agonist therapy with lower incidence of hepatitis $\mathrm{C}$ virus infection in young adult injection drug users. JAMA internal medicine. 2014;174(12): 1974-1981.

3. Birnbaum HG, White AG, Schiller M, Waldman T, Cleveland JM, Roland CL. Societal costs of prescription opioid abuse, dependence, and misuse in the United States. Pain Med. 2011;12(4):657-667.

4. Roland CL, Joshi AV, Mardekian J, Walden SC, Harnett J. Prevalence and cost of diagnosed opioid abuse in a privately insured population in the United States. J Opioid Manag. 2013;9(3):161-175.

5. Hagemeier NE. Introduction to the opioid epidemic: the economic burden on the healthcare system and impact on quality of life. Am J Manag Care. 2018;24(10 Suppl):S200-s206.

6. Johnson RE, Jaffe JH, Fudala PJ. A controlled trial of buprenorphine treatment for opioid dependence. Jama. 1992;267(20):2750-2755.

7. Kosten TR, Schottenfeld R, Ziedonis D, Falcioni J. Buprenorphine versus methadone maintenance for opioid dependence. Journal of Nervous and Mental Disease. 1993.

8. Krupitsky E, Nunes EV, Ling W, Gastfriend DR, Memisoglu A, Silverman BL. Injectable extended-release naltrexone (XR-NTX) for opioid dependence: long-term safety and effectiveness. Addiction. 2013;108(9):1628 1637.

9. Krupitsky E, Nunes EV, Ling W, Illeperuma A, Gastfriend DR, Silverman BL. Injectable extended-release naltrexone for opioid dependence: a double-blind, placebo-controlled, multicentre randomised trial. The Lancet. 2011;377(9776): 1506-1513.

10. Ling W, Charuvastra C, Collins JF, et al. Buprenorphine maintenance treatment of opiate dependence: a multicenter, randomized clinical trial. Addiction. 1998;93(4):475-486.

11. Ling W, Wesson DR, Charuvastra C, Klett CJ. A controlled trial comparing buprenorphine and methadone maintenance in opioid dependence. Archives of general psychiatry. 1996;53(5):401-407.

12. Mattick RP, Breen C, Kimber J, Davoli M. Methadone maintenance therapy versus no opioid replacement therapy for opioid dependence. Cochrane database of systematic reviews. 2009(3).

13. Jones C, Campopiano M, Baldwin G, McCance-Katz E. National and state treatment need and capacity for opioid agonist medication-assisted treatment [research-article]. In:2015. 
14. Knudsen HK, Abraham AJ, Roman PM. Adoption and implementation of medications in addiction treatment programs. J Addict Med. 2011;5(1):21-27.

15. Oliva EM, Harris AH, Trafton JA, Gordon AJ. Receipt of opioid agonist treatment in the Veterans Health Administration: facility and patient factors. Drug Alcohol Depend. 2012;122(3):241-246.

16. Oliva EM, Maisel NC, Gordon AJ, Harris AH. Barriers to use of pharmacotherapy for addiction disorders and how to overcome them. Current psychiatry reports. 2011;13(5):374.

17. Wyse JJ, Gordon AJ, Dobscha SK, et al. Medications for opioid use disorder in the Department of Veterans Affairs (VA) health care system: Historical perspective, lessons learned, and next steps. Subst Abus. 2018;39(2):139-144.

18. Safety VHAOoGaP. Management of Substance Use Disorder VA/DoD Clinical Practice Guidelines (SUD). https://vaww.qps.med.va.gov/divisions/qm/ebp/cpgSUD.aspx. Published 2021. Accessed September 22, 2021.

19. Becker WC, Fiellin DA. When Epidemics Collide: Coronavirus Disease 2019 (COVID-19) and the Opioid Crisis. Annals of internal medicine. 2020;173(1):59-60.

20. Gordon AJ, Kavanagh G, Krumm M, et al. Facilitators and barriers in implementing buprenorphine in the Veterans Health Administration. Psychol Addict Behav. 2011;25(2):215-224.

21. Stetler CB, Legro MW, Rycroft-Malone J, et al. Role of" external facilitation" in implementation of research findings: a qualitative evaluation of facilitation experiences in the Veterans Health Administration. Implementation Science. 2006;1(1): 1-15.

22. Hagedorn H, Dieperink E, Dingmann D, et al. Integrating hepatitis prevention services into a substance use disorder clinic. Journal of substance abuse treatment. 2007;32(4):391-398.

23. Hagedorn HJ, Rettmann N, Dieperink E, Knott A, Landon BE. A training model for implementing hepatitis prevention services in substance use disorder clinics: a qualitative evaluation. Journal of general internal medicine. 2015;30(8):1215-1221

24. Kirchner JE, Ritchie MJ, Pitcock JA, Parker LE, Curran GM, Fortney JC. Outcomes of a partnered facilitation strategy to implement primary caremental health. J Gen Intern Med. 2014;29 Suppl 4(Suppl 4):904-912.

25. Hagedorn H, Kenny M, Gordon AJ, et al. Advancing pharmacological treatments for opioid use disorder (ADaPT-OUD): protocol for testing a novel strategy to improve implementation of medication-assisted treatment for veterans with opioid use disorders in low-performing facilities. Addict Sci Clin Pract. 2018;13(1):25.

26. Rural-Urban Commuting Area Codes. United States Department of Agriculture Economic Research Service. . https://www.ers.usda.gov/ data-products/rural-urban-commuting-area-codes.aspx. Accessed October 2, 2021 .
27. Bazzoli GJ, Shortell SM, Dubbs N, Chan C, Kralovec P. A taxonomy of health networks and systems: bringing order out of chaos. Health services research. 1999;33(6): 1683.

28. Dubbs NL, Bazzoli GJ, Shortell SM, Kralovec PD. Reexamining organizational configurations: An update, validation, and expansion of the taxonomy of health networks and systems. Health Services Research. 2004;39(1):207-220.

29. Pinnock H, Barwick M, Carpenter CR, et al. Standards for reporting implementation studies (StaRI) statement. bmj. 2017;356.

30. Miles M, Huberman A, Saldana J. Qualitative data analysis: a methods sourcebook. 4th Edition ed. Thousand Oaks, CA: Sage Publishing Inc; 2019.

31. Gale RC, Wu J, Erhardt T, et al. Comparison of rapid vs in-depth qualitative analytic methods from a process evaluation of academic detailing in the Veterans Health Administration. Implementation Science. 2019;14(1): 11

32. Gustavson AM, Wisdom JP, Kenny ME, et al. Early impacts of a multifaceted implementation strategy to increase use of medication treatments for opioid use disorder in the Veterans Health Administration. Implementation science communications. 2021;2(1):1-13.

33. Hamilton $\mathrm{AB}$, Brunner J, Cain $\mathrm{C}$, et al. Engaging multilevel stakeholders in an implementation trial of evidence-based quality improvement in VA women's health primary care. Transl Behav Med. 2017;7(3):478-485.

34. Saloner B, Andraka Christou B, Gordon AJ, Stein BD. It will end in tiers: A strategy to include "dabblers" in the buprenorphine workforce after the X-waiver. Substance Abuse. 2021:1-5.

35. Gordon AJ, Drexler K, Hawkins EJ, et al. Stepped Care for Opioid Use Disorder Train the Trainer (SCOUTT) initiative: Expanding access to medication treatment for opioid use disorder within Veterans Health Administration facilities. Substance Abuse. 2020;41(3):275-282.

36. Consortium to Disseminate and Understand Implementation of Opioid Use Disorder (OUD) Treatment. . United States Department of Veteran Affairs, Quality Enhancement Research Initiative. https://www.queri. research.va.gov/centers/CONDUIT.pdf. Accessed October 2, 2021.

37. Powell BJ, Waltz TJ, Chinman MJ, et al. A refined compilation of implementation strategies: results from the Expert Recommendations for Implementing Change (ERIC) project. Implementation Science. 2015;10(1):1-14.

38. Proctor EK, Powell BJ, McMillen JC. Implementation strategies: recommendations for specifying and reporting. Implement Sci. 2013;8:139.

Publisher's Note Springer Nature remains neutral with regard to jurisdictional claims in published maps and institutional affiliations. 